\title{
Four lateral mass screw fixation techniques in lower cervical spine following laminectomy: a finite element analysis study of stress distribution
}

\author{
Mingzhi Song ${ }^{1}$, Zhen Zhang ${ }^{1}$, Ming Lu' ${ }^{1}$, Junwei Zong ${ }^{1}$, Chao Dong ${ }^{2}$, Kai Ma ${ }^{1 *+}$ and Shouyu Wang ${ }^{1 *+}$
}

* Correspondence:
dmu_makai@sina.com;
dmuwsy@sina.com
${ }^{+}$Equal contributors
${ }^{1}$ Department of Orthopedics, The
First Affiliated Hospital of Dalian
Medical University, 222 Zhongshan
Road, Dalian 116011, P.R. China
Full list of author information is
available at the end of the article

() Biomed Central

\begin{abstract}
Background: Lateral mass screw fixation (LSF) techniques have been widely used for reconstructing and stabilizing the cervical spine; however, complications may result depending on the choice of surgeon. There are only a few reports related to LSF applications, even though fracture fixation has become a severe complication. This study establishes the three-dimensional finite element model of the lower cervical spine, and compares the stress distribution of the four LSF techniques (Magerl, Roy-Camille, Anderson, and An), following laminectomy - to explore the risks of rupture after fixation.
\end{abstract}

Method: CT scans were performed on a healthy adult female volunteer, and Digital imaging and communication in medicine (Dicom) data was obtained. Mimics 10.01, Geomagic Studio 12.0, Solidworks 2012, HyperMesh 10.1 and Abaqus 6.12 software programs were used to establish the intact model of the lower cervical spines (C3-C7), a postoperative model after laminectomy, and a reconstructive model after applying the LSF techniques. A compressive preload of $74 \mathrm{~N}$ combined with a pure moment of $1.8 \mathrm{Nm}$ was applied to the intact and reconstructive model, simulating normal flexion, extension, lateral bending, and axial rotation. The stress distribution of the four LSF techniques was compared by analyzing the maximum von Mises stress.

Result: The three-dimensional finite element model of the intact C3-C7 vertebrae was successfully established. This model consists of 503,911 elements and 93,390 nodes. During flexion, extension, lateral bending, and axial rotation modes, the intact model's angular intersegmental range of motion was in good agreement with the results reported from the literature. The postoperative model after the three-segment laminectomy and the reconstructive model after applying the four LSF techniques were established based on the validated intact model. The stress distribution for the Magerl and Roy-Camille groups were more dispersive, and the maximum von Mises stress levels were lower than the other two groups in various conditions.

Conclusion: The LSF techniques of Magerl and Roy-Camille are safer methods for stabilizing the lower cervical spine. Therefore, these methods potentially have a lower risk of fixation fracture.

Keywords: Finite element, Fixation, Lower cervical spine, Laminectomy, Biomechanics 


\section{Background}

With the steady development of internal fixation techniques, lateral mass screw fixation (LSF) with plates or rods has become the standard method for posterior cervical spine fixation and stability on various surgical indications. Many studies emphasized that LSF techniques could provide the same biomechanical stability, as compared with anterior cervical fixations or posterior wiring techniques. Additionally, due to the development of the polyaxial screw-rod system, cervical fixation surgery has now become easy to perform. Therefore, most surgeons believe the LSF techniques are the optimum methods for reconstructing the stability of the cervical spine, following decompressive surgery $[1,2]$.

LSF techniques have been constantly studied and modified, since it was first introduced by Roy-Camille in 1972; and the techniques of Magerl, Anderson and An were extensively used as well. Even though numerous anatomical and clinical studies pointed out that the techniques of Roy-Camille and Magerl had the best practical applications, inevitable and undesirable complications still occurred, such as adjacent facet joint injury, nerve root, and vertebral artery or screw loosening and fracture [3]. In fact, all LSF techniques may result to diverse complications, depending on the surgeon's optimization of the LSF techniques $[4,5]$. For the last two decades, many studies have evaluated the advantages of different LSF techniques, based on its complications [6-8]. However, we are unaware of any report that directly compares LSF techniques by analyzing fixation fractures as a severe complication - which has a relatively low incident rate $[9,10]$.

Due to limited case reports, it is rare find studies related to the fixation fractures of the LSF system; making it impossible to have a case analysis and difficult to simulate by traditional cadaveric experiments. A novel biomechanical approach by computer could provide a possible way to reveal the rupture risks of fixation in different LSF techniques. In recent years, finite element (FE) analysis is a technique that has been generally adopted by orthopedic experts to address biomechanical problems, especially for stress distribution [11-13]. The CT scan data obtained from a healthy volunteer was used in our study; and the four LSF techniques were applied to establish reconstructive FE models of the lower cervical spine, after a three-segment (C4-C6) laminectomy. The biomechanical stress distribution of the reconstructed models were analyzed by applying different LSF techniques via FE analysis - aiming to provide experimental and theoretical reference for choosing the LSF technique for the lower cervical spine.

\section{Materials and methods}

\section{Establishment of the intact FE model}

This study was assessed and approved by the Ethics Committee of the First Affiliated Hospital of Dalian Medical University. CT scan data, with a space interval of $0.625 \mathrm{~mm}$, was obtained from a thirty-year-old healthy female volunteer in an unloaded neutral position. The C3-C7 data, saved in Dicom format, was imported into the Mimics 10.01 (Materialise company, Belgium) software. A threshold was established to differentiate bone and soft tissue. Boolean calculation and interactive three-dimensional manual/automatic cutting operations were performed to establish a rough three-dimensional (3D) model of C3-C7. The model was polished, filled, and denoised by using Geomagic Studio 12.0 software (Raindrop company, USA) to smoothen uneven surfaces - caused by stacking CT 
images. To reconstruct the missing physiological lordosis caused by the unloaded position, we entered the model into the Solidworks 2012 (DSSolidWorks company, USA) software to adjust the positioning of each cervical vertebra. HyperMesh 10.1 (Altair company, USA) software was used to simulate the cured surface contour of the vertebral body and intervertebral disc; then the model was meshed into a solid model. Finally, the model was imported into the FE software, Abaqus 6.12 (Simulia corp, USA), for element setup, material properties definition and FE analysis (Figure 1).

Posterior elements, cancellous bone, annulus fibrosus, nucleus pulposus, and tetrahedral elements were used for modeling vertebral bodies; cartilaginous endplates and shell elements were used for the vertebral body's cortical bone. Ligaments were simulated as nonlinear tension-only connectors. The facet articulations of the eight pairs of zygapophyseal joints in the $\mathrm{C} 3-\mathrm{C} 7$ vertebrae were simulated as frictionless contact elements, due to its infinitesimal friction. The material properties of the vertebra, intervertebral disc and ligament are shown in Tables 1 and 2, according to the data reported by the reference literature [14-16].

\section{Validation of the intact 3D FE model}

While the superior surface of the C3 vertebra was free, a boundary condition constraining all degrees of freedom was applied to the inferior surface of the $\mathrm{C} 7$ vertebra. A compressive preload of 74 $\mathrm{N}$ combined with a pure moment of $1.8 \mathrm{Nm}$ [17] was applied on the superior surface of the C3 vertebra to simulate flexion, extension, left-right lateral bending, and left-right axial rotation movements. Abaqus 6.12 was used to validate the model by comparing the intersegmental range of motion measured from this model with the figures published by Moroney [17], Panjabi [18] and Finn [19]. If the model's parameters are in good agreement with the normal parameters of the human body, this intact model could be used for further research.

\section{Laminectomy simulation and the establishment of reconstructive models}

Laminectomy was simulated in Solidworks 2012 software, which was designed to excise the lamina at C4-C6 vertebrae, the ligamentum flavum, and the spinous ligamentum at C3-C7 vertebrae. The model was built after laminectomy. $14 \mathrm{~mm}$ diameter screws and

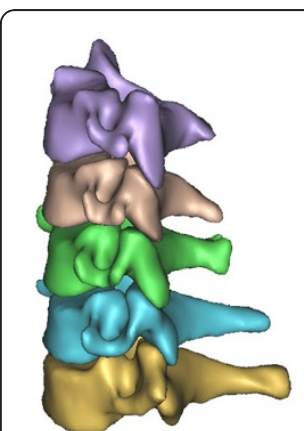

A

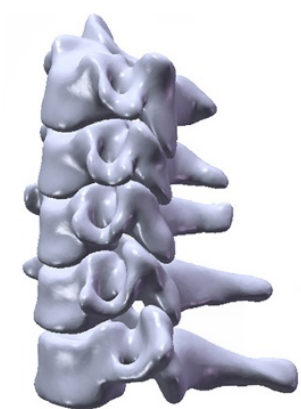

B

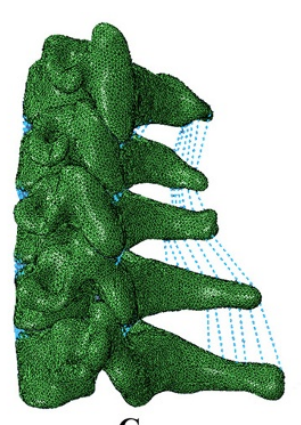

C

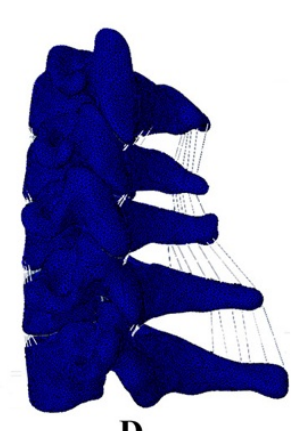

D

Figure 1 The procedure to establish the intact 3D FE model: A: the primary model of the normal lower cervical vertebra, B: the intact model of the lower cervical spine after recovering the physiological lordosis, C: the meshed finite element of the lower cervical spine, D: the model to simulate physiological movement. 
Table 1 Material and mechanical properties of the different parts used for the finite element model

\begin{tabular}{ccc}
\hline Components & Young's modulus (MPa) & Poisson's ratio \\
\hline Cortical bone & 10000.0 & 0.29 \\
Cancellous bone & 100.0 & 0.29 \\
Endplate & 500.0 & 0.40 \\
Posterior structure & 3500.0 & 0.29 \\
Annulus fibrosus & 3.4 & 0.40 \\
Nucleus pulposus & 1.0 & 0.49 \\
Internal fixation devices (titanium alloy) & 145000.0 & 0.30 \\
\hline
\end{tabular}

longitudinal connecting rods bending from $0^{\circ}$ to $20^{\circ}$ were designed by using the software. After laminectomy, internal fixation systems were implanted in the models at C4-C6 by applying four LSF techniques (Figure 2). During the procedure, the bone substance of the screw's trajectory was eliminated, the screw was implanted, and each component of the internal fixation device was adjusted under direct visualization. Based on the physiological lordosis measured from the reconstructive model, we chose the bending $8^{\circ}$ connecting rod to connect the adjacent screws.

The reconstructive models were defined as Magerl, Roy-Camille, Anderson and An groups, based on the LSF technique applied. Finally, Boolean calculation and mesh generation of the skeleton were performed, as well as the application of internal fixation devices. Elements setup, material properties definition and FE algorithms were implemented.

\section{Biomechanical comparison and stress analysis}

The same boundary and loading conditions were applied to the four models. A compressive preload of $74 \mathrm{~N}$ combined with a pure moment of $1.8 \mathrm{Nm}$ was applied to

Table 2 Mechanical properties of the main ligaments for the finite element model

\begin{tabular}{|c|c|c|c|c|c|c|c|c|c|c|}
\hline \multirow{3}{*}{$\begin{array}{l}\text { Deflection } \\
(\mathrm{mm})\end{array}$} & \multicolumn{10}{|c|}{ Force $(N)$} \\
\hline & \multicolumn{2}{|c|}{$\begin{array}{c}\text { Anterior } \\
\text { longitudinal }\end{array}$} & \multicolumn{2}{|c|}{$\begin{array}{c}\text { Posterior } \\
\text { longitudinal }\end{array}$} & \multicolumn{2}{|c|}{ Spinous } & \multicolumn{2}{|c|}{$\begin{array}{l}\text { Ligamentum } \\
\text { flavum }\end{array}$} & \multicolumn{2}{|c|}{ Capsular } \\
\hline & C3-C7 & $\mathrm{C} 5-\mathrm{C} 7$ & C3-C5 & $\mathrm{C} 5-\mathrm{C7}$ & $\mathrm{C} 3-\mathrm{C} 5$ & $\mathrm{C} 5-\mathrm{C7}$ & C3-C5 & C5-C7 & $\mathrm{C} 3-\mathrm{C} 5$ & $\mathrm{C} 5-\mathrm{Cl}$ \\
\hline 0 & 0.0 & 0.0 & 0.0 & 0.0 & 0.0 & 0.0 & 0.0 & 0.0 & 0.0 & 0.0 \\
\hline 1 & 28.0 & 20.0 & 25.0 & 20.0 & 7.0 & 8.0 & - & - & - & - \\
\hline 2 & 52.0 & 40.0 & 44.0 & 40.0 & 12.5 & 14.0 & 38.0 & 30.0 & 55.0 & 75.0 \\
\hline 3 & 72.0 & 58.0 & 62.0 & 60.0 & 18.0 & 20.0 & - & - & - & - \\
\hline 4 & 89.0 & 78.0 & 78.0 & 78.0 & 22.5 & 25.0 & 60.0 & 68.0 & 130.0 & 145.0 \\
\hline 5 & 102.0 & 98.0 & 89.0 & 92.0 & 26.0 & 29.0 & - & - & - & - \\
\hline 6 & 115.0 & 112.0 & - & - & 30.0 & 32.5 & 80.0 & 102.0 & 180.0 & 204.0 \\
\hline 7 & - & - & 32.5 & 35.0 & - & - & - & - & - & - \\
\hline 8 & - & - & - & - & - & - & 108.0 & 130.0 & 210.0 & 250.0 \\
\hline 9 & - & - & - & - & - & - & - & - & - & - \\
\hline 10 & - & - & - & - & - & - & - & - & 230.0 & 265.0 \\
\hline
\end{tabular}




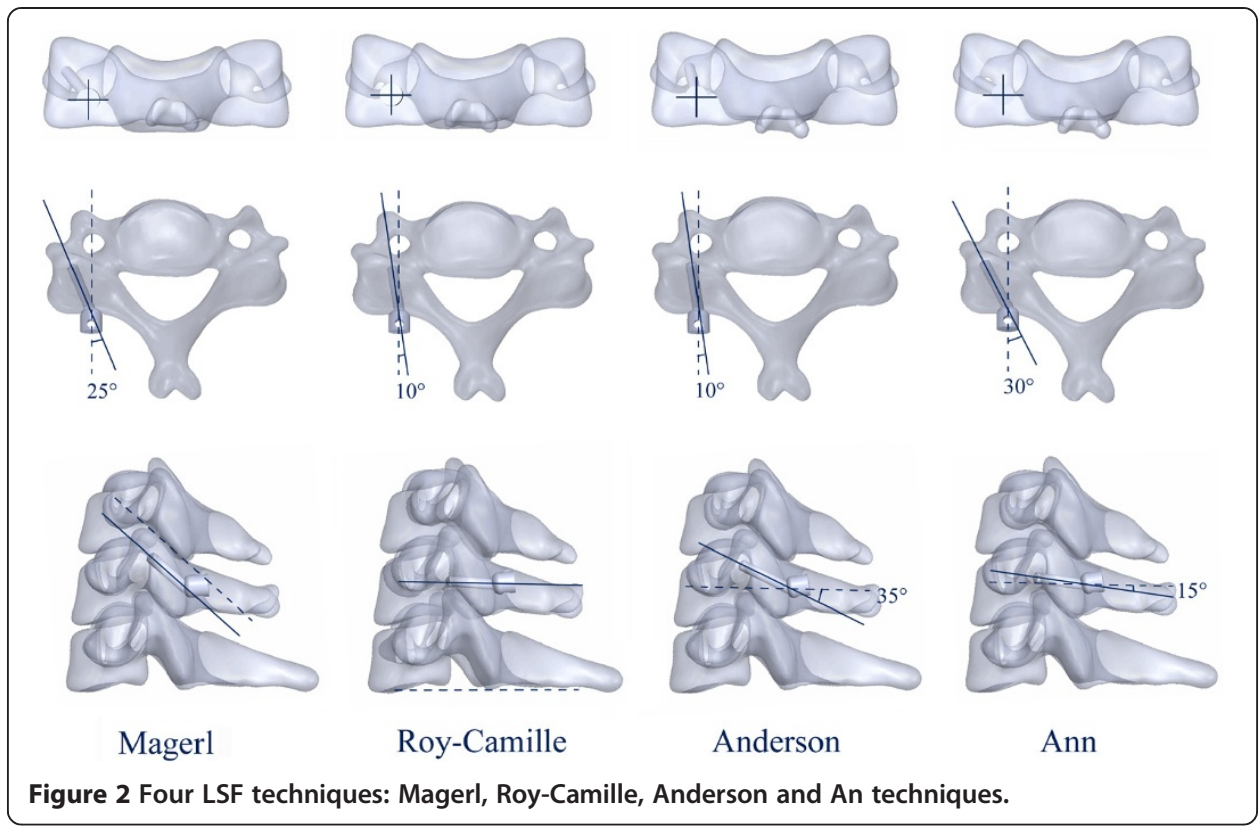

simulate flexion, extension, lateral bending and axial rotation. A stress distribution analysis of each fixation technique was implemented by using Abaqus 6.12.

\section{Results}

\section{FE modeling and validation}

The intact 3D FE model of C3-C7 vertebrae was successfully established through CT scan and digital image processing, while utilizing Mimics 10.01, Geomagic Studio 12.0, Solidworks 2012, HyperMesh 10.1 and Abaqus 6.12 (Figure 1). The model contained five cervical vertebrae, four cervical intervertebral discs and five ligaments; which also consisted of 503,911 elements and 93,390 nodes (Table 3). Figure 3 shows the in vitro data details used for the comparison. The comparison of the angular intersegmental motion between the intact model and previously published data under the combined flexion, extension, left-right lateral bending and left-right axial rotation modes were summarized. There were no obvious differences (Figure 3) in the angular intersegmental range

Table 3 C3-C7 finite element model grid information

\begin{tabular}{cccr}
\hline Part instance & Element type & Element & Node \\
\hline C3 & C3D4(S3) & 92250 & 16975 \\
C4 & C3D4(S3) & 89542 & 16509 \\
C5 & C3D4(S3) & 94226 & 17375 \\
C6 & C3D4(S3) & 105076 & 19333 \\
C7 & C3D4(S3) & 116581 & 21378 \\
Disc3/4 & C3D4(S3) & 2159 & 548 \\
Disc4/5 & C3D4(S3) & 2264 & 596 \\
Disc5/6 & C3D4(S3) & 2075 & 534 \\
Disc6/7 & C3D4(S3) & 2358 & 605 \\
Total & C3D4(S3) & 503911 & 93390 \\
\hline
\end{tabular}




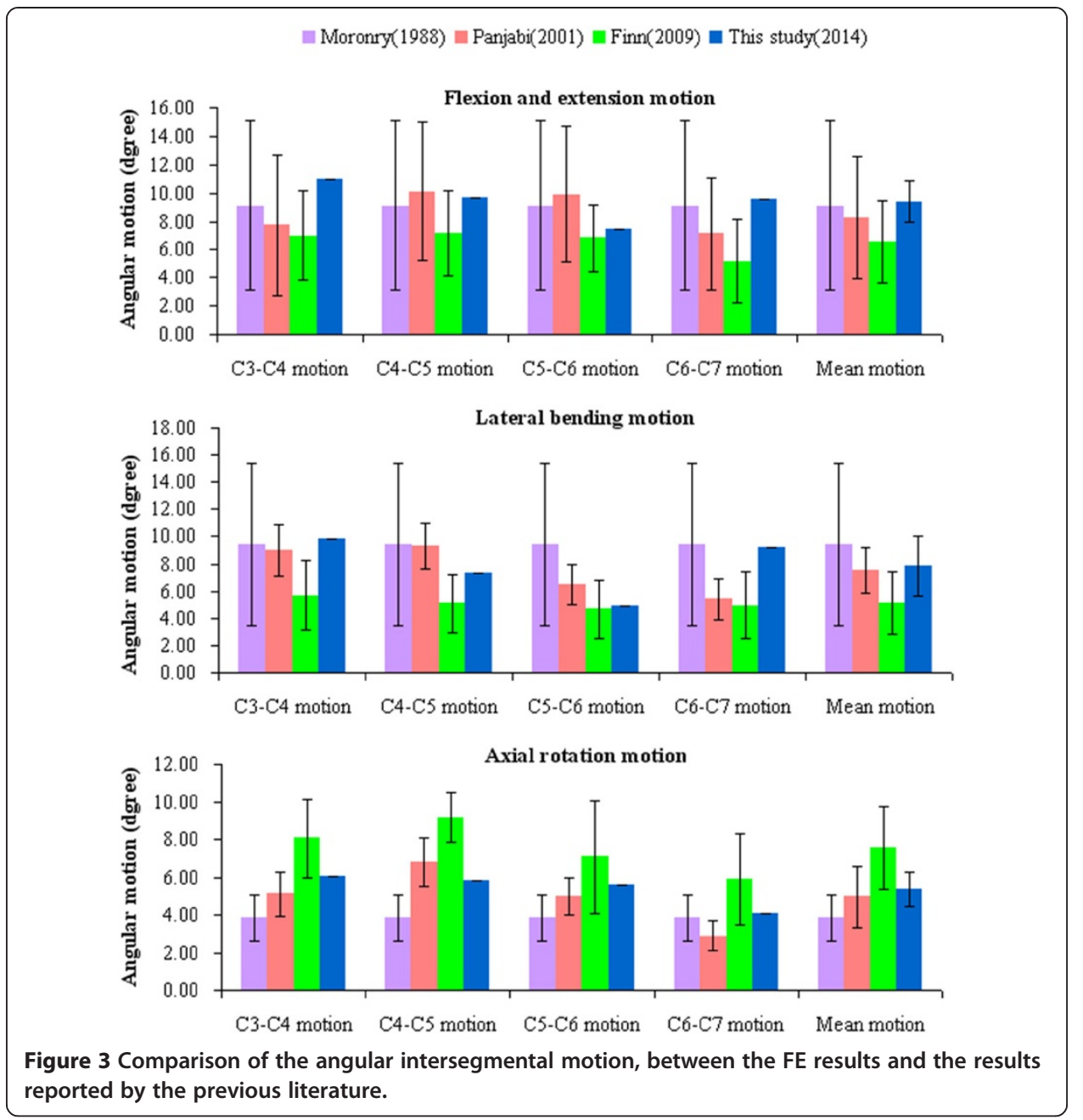

of motion between the intact model and the data published by the literature [17-19]. The data was conformed through normal human body parameters. Therefore, the intact FE model could simulate the physiological movement of the cervical vertebra, and this model can be used for our further studies.

\section{FE model surgery simulation}

Based on the validated intact model, the lower cervical spine model after a threesegment laminectomy and the reconstructive model applied with the four LSF techniques were established. Multi-directional screws and connecting rods were designed in Solidworks 2012. During the simulated procedure, the bone substance of the screw's trajectory was eliminated, the screw was implanted, and each component of the internal fixation device was adjusted. The surface between the screw and the trajectory was simulated by imposing an ideal rough behavior (infinite friction coefficient). Based on the physiological lordosis measured from the reconstructive model, we chose the bending $8^{\circ}$ connecting rod to connect the adjacent screws (Figure 4). The re-meshed models were established by using Hypermesh (Figure 5). 


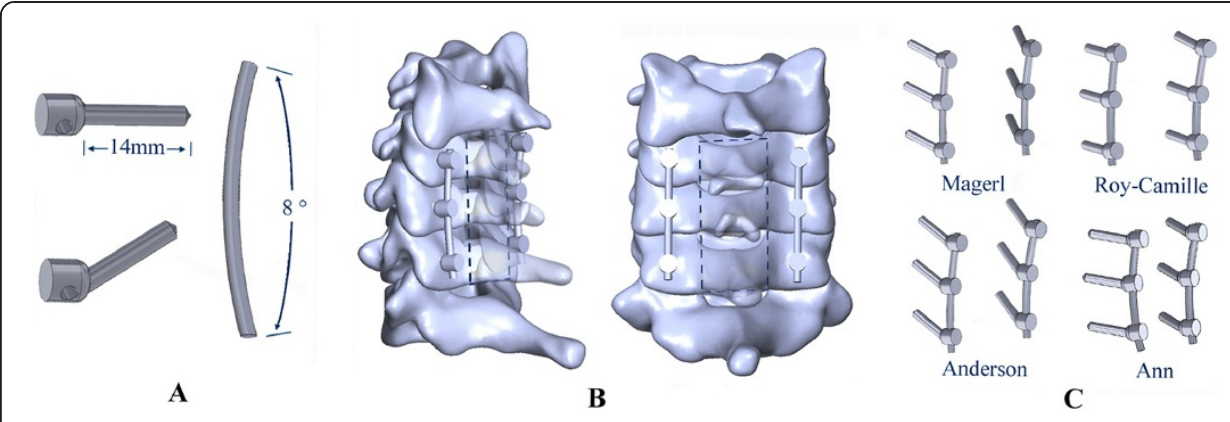

Figure 4 Design process of the internal fixation device and resection and assembly process of the FE model. A: multi-directional screws and connecting rod. B: resection area of the three-segment laminectomy. C: different fixation devices for the four LSF techniques.

\section{Stress analysis}

The stress distribution on the fixation devices could demonstrate the risks of fracture, according to the fixation techniques. Figure 6 shows the stress distribution levels of the four different fixation devices during flexion, extension, left-right lateral bending, and left-right axial rotating conditions. Fixation location effects on load transfers can be evaluated based on stress concentration. Figure 7 shows the maximum von Mises stress comparisons among the fixation techniques in flexion, extension, left-right lateral bending, and leftright axial rotating conditions. For all reconstructive models, extended movement added more stress to the internal fixation system. We noted that the stress distribution in the fixation of Magerl and Roy-Camille groups were more dispersive than the other two groups (Figure 7). Higher stress concentrated areas were observed on the upper-side of connecting rod and in the rod-screw's interface for the An and Anderson groups, especially during extension and left-right axial rotating conditions. The maximum stress level for the Anderson and An techniques in extended conditions were 99.32 $\mathrm{MPa}$ and 96.45 $\mathrm{MPa}$, respectively (Table 4). However, the maximum stress levels for Magerl and Roy-Camille were less than $90 \mathrm{MPa}$ in extended conditions. Differences were also noticeable during flexion and axial rotating conditions. In each condition, the fixation device obtained a higher level of maximum stress from the Anderson and An techniques, which indicates that Magerl and Roy-Camille LSF techniques incurs lower risks of screw fracture.

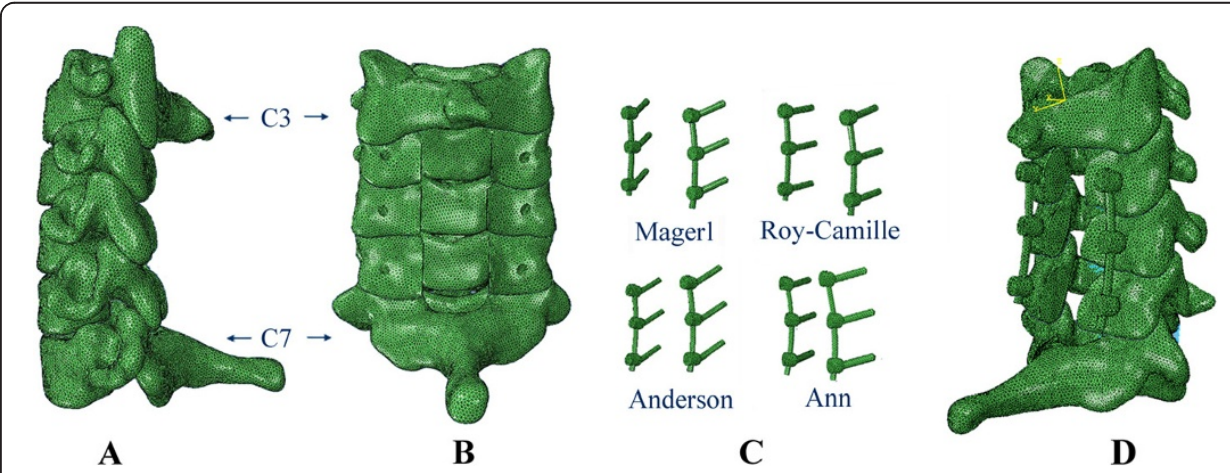

Figure 5 The re-meshed model and internal fixation devices. A, B: re-meshed FE model of the lower cervical spine following laminetomy. C: meshed fixation devices. D: re-meshed reconstructive FE model following LSF techniques. 


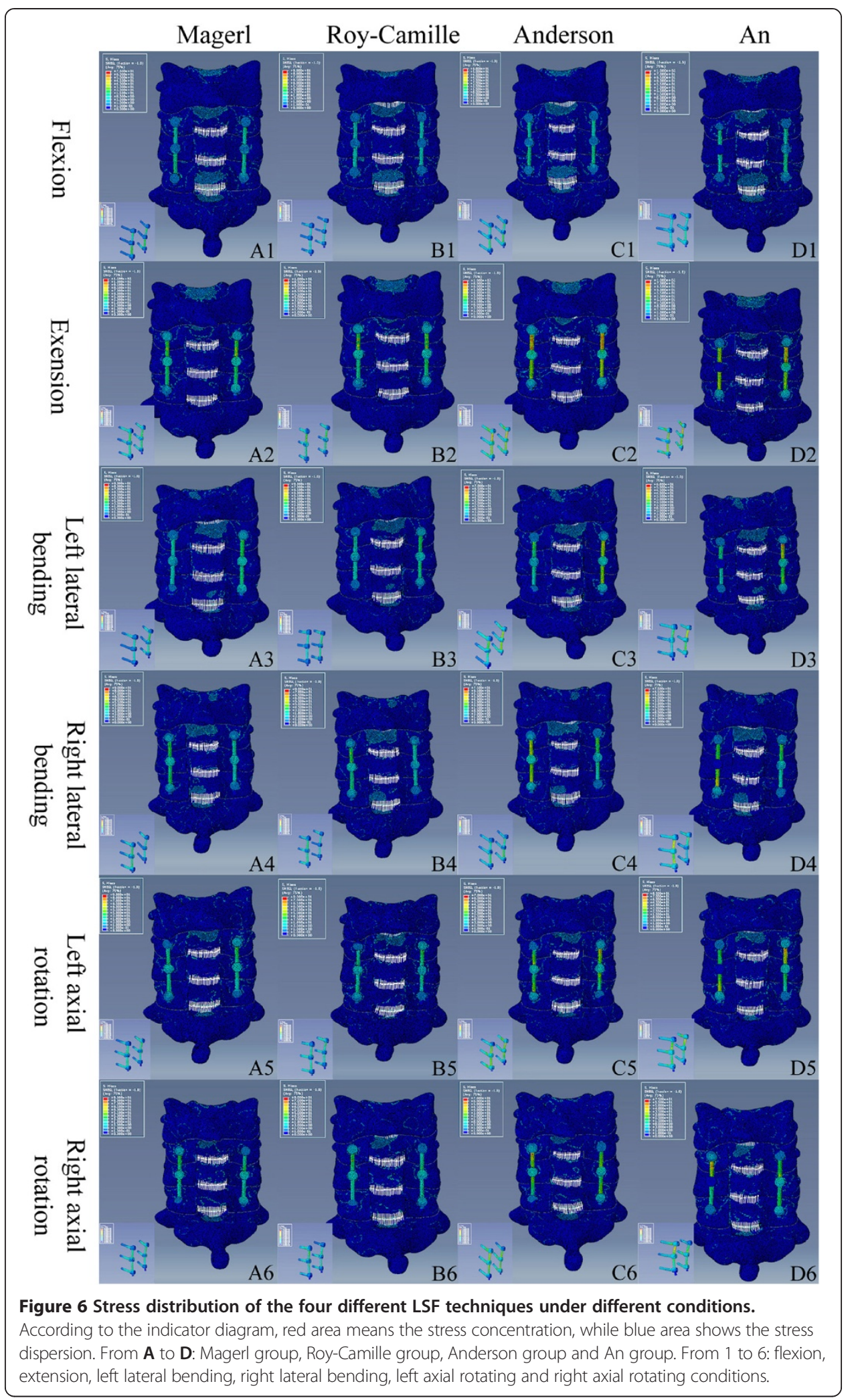




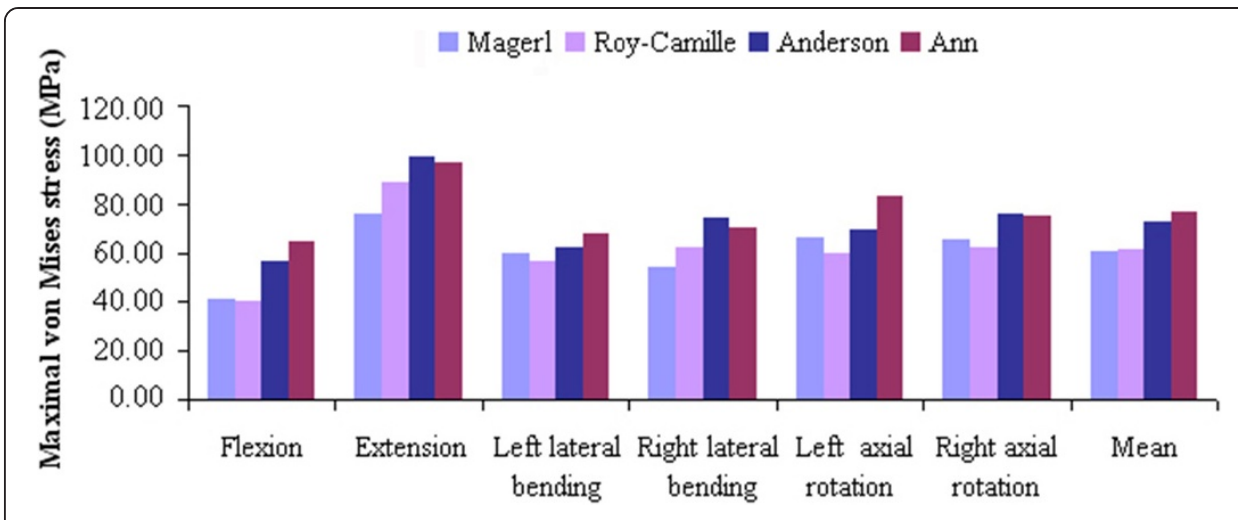

Figure 7 The von Mises stress of the four LSF techniques under various loading conditions.

\section{Discussion}

The 3D FE model is expected to provide theoretical reference for clinical practice. We established an intact model of the lower cervical spine (C3-C7) that contained bony structures, annulus fibrosus, nucleus pulposus and related ligaments (i.e. anterior and posterior longitudinal ligaments, ligamentum flavum, spinous ligament, and capsular ligaments). The intact model consisted of 503,911 elements and 93,390 nodes (Table 3), which were more elaborate than the previous models [20-23]. We simulated ligamentous structures based on the biomechanical data that was previously reported [24] and ligament functions were simulated as uniaxial nonlinear element connections. The physiological lordosis, caused by its unloaded position, recovered to accord with the authentic biomechanics of the human vertical spine. The intact model's angular intersegmental range of motions was in good agreement with the data reported by the literature [17-19]. These results validated the model and that this model could be used for other analysis. Additionally, the mesh quantity determines the accuracy of the biomechanical analysis; our FE model promises better results in our future studies.

Based on the validated model, laminectomy was simulated to establish the postoperative model, and the four reconstructive models using the four different techniques (i.e. Roy-Camille, Magerl, Anderson, and An techniques). All simulations were performed in Solidworks 2012. With its powerful design and assembly functions, the reconstructive models were established more accurately. Fault recognition was effectively avoided, when files were exported to the other software programs - due to its software processing.

Magerl, Anderson, and An techniques were based on the Roy-Camille technique. The biomechanical stability of all four techniques could provide similar results, so as not to

Table 4 The maximal von Mises stress data of four LSF techniques under various loading conditions ( $\mathrm{MPa})$

\begin{tabular}{cccccccc}
\hline $\begin{array}{c}\text { Different } \\
\text { groups }\end{array}$ & Flexion & Extension & $\begin{array}{c}\text { Left lateral } \\
\text { bending }\end{array}$ & $\begin{array}{c}\text { Right lateral } \\
\text { bending }\end{array}$ & $\begin{array}{c}\text { Left axial } \\
\text { rotation }\end{array}$ & $\begin{array}{c}\text { Right axial } \\
\text { rotation }\end{array}$ & Mean \\
\hline Magerl & 41.26 & 75.45 & 59.32 & 54.16 & 66.14 & 65.38 & 60.29 \\
Roy-Camille & 40.36 & 88.64 & 56.13 & 62.07 & 59.26 & 62.39 & 61.48 \\
Anderson & 56.04 & 99.32 & 62.30 & 74.06 & 69.42 & 75.67 & 72.80 \\
An & 64.25 & 96.45 & 67.96 & 70.04 & 83.21 & 74.89 & 76.21 \\
\hline
\end{tabular}


destroy the nucleus pulposus. In recent years, the comparisons of the above four LSF techniques mainly focused on the following aspects, facet joint violation, nerve injury, vertebral artery injury and screw pullout force. Firstly, for the facet joint violation, the point of entry and orientation of the screw were different from the four techniques. The facet joint may be violated during the screw's implantation. Studies $[25,26]$ have shown that approximately $50 \%$ of patients had complications due to facet joint violation, after undergoing fixation surgery with the technique of Roy-Camille. However, these complications rarely happened to patients who underwent fixation surgery using the Magerl and Anderson techniques. Secondly, for nerve injury, chronic postoperative neck pain may occur in patients after undergoing surgery with the technique of Magerl. This symptom occurs due the protrusion of the screw tip, which is close to the dorsal branch of the nerve root $[27,28]$. Xu et al. reported that potential risks of nerve root violation were higher in patients who underwent the Magerl and Anderson techniques, than the An technique [29]. The potential risk of nerve root injury was lower in patients who used the Roy-Camille technique, than the Magerl technique [30]. Third, for the vertebral artery injury, due to the distance of the vertebral artery from the screw's trajectory, this artery is not likely to get injured. Heller et al. [30] found that the vertebral arteries of 26 cadaver specimens were not threatened, after undergoing LSF surgery of the lower cervical spine with the techniques of Roy-Camille and Magerl. Based on the findings of Heller, Katonis et al. [4] found no cases of vertebral artery injury among the 225 patients who underwent LSF surgery. Lastly, although comparisons had been previously conducted, the pullout force of the implanted screws, with the application of different LSF techniques, is still controversial [31]. Ulrich et al. [32] found that the imprecise fixation of screws could decrease the pullout force while undergoing surgery with the Roy-Camille technique. Magerl and An techniques paid more attention to the orientation of the screw to acquire the maximum pullout force - fixing these screws firmly to prevent extraction [25].

At present, there are still no reports on stress distribution comparisons for the four LSF techniques following laminectomy in the lower cervical spine - for neither cadaveric study nor FE analysis. In our study, the FE analysis showed obvious differences among the four LSF techniques in response to stress distribution and maximum von Mises stress. Under various loading conditions, stress distribution in both Magerl and Roy-Camille groups were more dispersive as compared with the other two groups. The fixations in the Anderson and An groups had higher stress concentrations on the upper-side of the connecting rods and in the rod-screw's interface. The difference of the screw's point of entry and orientation contribute mostly to the difference in stress distribution. However, there were no significant stress distribution differences between the Magerl and Roy-Camille groups, and the Anderson and An groups. The maximum von Mises stress in the Anderson and An groups were obviously higher than the other two groups - especially under extension and left-right axial rotating conditions. Nearly $100 \mathrm{MPa}$ was concentrated on the upper side of the rod, which led to higher risks of fracture. According to the comprehensive analysis above, fixation by Magerl and Roy-Camille techniques were safer than the Anderson and An techniques. These conformed results were based on the routine choice of surgeons [3]. Although, the Magerl and Roy-Camille techniques are still better, looking from the standpoint of stress distribution. 


\section{Conclusion}

In summary, stress distribution was more dispersive and the maximum von Mises stress levels were lower in the Magerl and Roy-Camille groups for various conditions. Magerl and Roy-Camille techniques were safer for stabilizing the lower cervical spine, due to its potentially low risk of fixation fracture. We also suggest that surgeons should use new alloy materials for fixation or should limit extension movement, to retain and yield better strength and to decrease the risk of fracture, when opting for applying the Anderson and An techniques.

\section{Abbreviations}

LSF: Lateral mass screw fixation; FE: Finite element; 3D: Three-dimensional; C3-C7: Lower cervical spine.

\section{Competing interests}

The authors declare that they have no competing interests.

\section{Authors' contributions}

SMZ and MK designed this study. Both of them carried out the finite element study, analyzed the results and drafted the manuscript. ZJW helped in drafting the manuscript. DC took part in the finite element analysis. ZZ and LM helped to revise the manuscript. WSY and MK mentored the finite element analysis and provided valuable suggestions in drafting the manuscript. They were all responsible for the project and the manuscript. All authors read and approved the final manuscript.

\section{Acknowledgement}

This study was supported by the National Natural Science Foundation of China (No. 81270052).

\section{Author details}

'Department of Orthopedics, The First Affiliated Hospital of Dalian Medical University, 222 Zhongshan Road, Dalian 116011 , P.R. China. ${ }^{2}$ School of Mechanical Engineering, Dalian Jiaotong University, 794 Huanghe Road, Dalian 116028 , P.R. China.

Received: 1 June 2014 Accepted: 1 August 2014

Published: 9 August 2014

\section{References}

1. Du W, Zhang P, Shen $Y$, Zhang YZ, Ding WY, Ren $L X$ : Enlarged laminectomy and lateral mass screw fixation for multilevel cervical degenerative myelopathy associated with kyphosis. Spine J 2014, 14(1):57-64.

2. Mikhael MM, Celestre PC, Wolf CF, Mroz TE, Wang JC: Minimally invasive cervical spine foraminotomy and lateral mass screw placement. Spine (Phila Pa 1976) 2012, 37(5):318-322.

3. Kim SH, Seo WD, Kim KH, Yeo HT, Choi GH, Kim DH: Clinical outcome of modified cervical lateral mass screw fixation technique. J Korean Neurosurg Soc 2012, 52(2):114-119.

4. Katonis P, Papadakis SA, Galanakos S, Paskou D, Bano A, Sapkas G, Hadjipavlou AG: Lateral mass screw complications: analysis of 1662 screws. J Spinal Disord Tech 2011, 24(7):415-420.

5. Inoue S, Moriyama T, Tachibana T, Okada F, Maruo K, Horinouchi Y, Yoshiya S: Risk factors for intraoperative lateral mass fracture of lateral mass screw fixation in the subaxial cervical spine. J Neurosurg Spine 2014, 20(1):11-17.

6. Merola AA, Castro BA, Alongi PR, Mathur S, Brkaric M, Vigna F, Riina JP, Gorup J, Haher TR: Anatomic considerations for standard and modified techniques of cervical lateral mass screw placement. Spine J 2002, 2(6):430-435.

7. Baek JW, Park DM, Kim DH: Comparative analysis of three different cervical lateral mass screw fixation techniques by complications and bicortical purchase : cadaveric study. J Korean Neurosurg Soc 2010, 48(3):193-198.

8. Nishinome $M$, lizuka $H$, lizuka $Y$, Takagishi $K$ : Anatomy of subaxial cervical foramens: the safety zone for lateral mass screwing. Eur Spine J 2012, 21(2):309-313.

9. Fehlings MG, Cooper PR, Errico TJ: Posterior plates in the management of cervical instability: long-term results in 44 patients. J Neurosurg 1994, 81(3):341-349.

10. Heller JG, Silcox DH, Sutterlin CE: Complications of posterior cervical plating. Spine (Phila Pa 1976) 1995, 20(22):2442-2448.

11. Palepu V, Kiapour A, Goel VK, Moran JM: A unique modular implant system enhances load sharing in anterior cervical interbody fusion: a finite element study. Biomed Eng Online 2014, 13(1):26.

12. Hong JT, Qasim M, Espinoza Orías AA, Natarajan RN, An HS: A biomechanical comparison of three different posterior fixation constructs used for C6-C7 cervical spine immobilization: A finite element study. Neurol Med Chir (Tokyo) 2014, Jan 10 [Epub ahead of print]. doi: 10.2176/nmc.0a.2013-0004.

13. Amornvit $P$, Rokaya $D$, Keawcharoen $K$, Thongpulsawasdi N: Stress distribution in implant retained finger prosthesis: a finite element study. $J$ Clin Diagn Res 2013, 7(12):2851-2854.

14. Zhang QH, Teo EC, Ng HW: Development and validation of a CO-C7 FE complex for biomechanical study. $J$ Biomech Eng 2005, 127(5):729-735.

15. Yoganandan N, Kumaresan S, Pintar FA: Biomechanics of the cervical spine Part 2. Cervical spine soft tissue responses and biomechanical modeling. Clin Biomech (Bristol, Avon) 2001, 16(1):1-27.

16. Hong-Wan N, Ee-Chon T, Qing-Hang Z: Biomechanical effects of C2-C7 intersegmental stability due to laminectomy with unilateral and bilateral facetectomy. Spine (Phila Pa 1976) 2004, 29(16):1737-1745. 
17. Moroney SP, Schultz AB, Miller JA, Andersson GB: Load-displacement properties of lower cervical spine motion segments. J Biomech 1988, 21(9):769-779.

18. Panjabi MM, Crisco JJ, Vasavada A, Oda T, Cholewicki J, Nibu K, Shin E: Mechanical properties of the human cervical spine as shown by three-dimensional load-displacement curves. Spine (Phila Pa 1976) 2001, 26(24):2692-2700.

19. Finn MA, Brodke DS, Daubs M, Patel A, Bachus KN: Local and global subaxial cervical spine biomechanics after single-level fusion or cervical arthroplasty. Eur Spine J 2009, 18(10):1520-1527.

20. Zhang QH, Teo EC, Ng HW, Lee VS: Finite element analysis of moment-rotation relationships for human cervical spine. J Biomech 2006, 39(1):189-193.

21. Zhang JG, Wang F, Zhou R, Xue Q: A three-dimensional finite element model of the cervical spine: an investigation of whiplash injury. Med Biol Eng Comput 2011, 49(2):193-201.

22. Faizan A, Goel VK, Garfin SR, Bono CM, Serhan H, Biyani A, Elgafy H, Krishna M, Friesem T: Do design variations in the artificial disc influence cervical spine biomechanics? A finite element investigation. Eur Spine J 2012, 21(Suppl 5):653-662.

23. Xie T, Qian J, Lu Y, Chen B, Jiang Y, Luo C: Biomechanical comparison of laminectomy, hemilaminectomy and a new minimally invasive approach in the surgical treatment of multilevel cervical intradural tumour: a finite element analysis. Eur Spine J 2013, 22(12):2719-2730

24. Yoganandan N, Kumaresan S, Pintar FA: Geometric and mechanical properties of human cervical spine ligaments. J Biomech Eng 2000, 122(6):623-629.

25. Reinhold M, Magerl F, Rieger M, Blauth M: Cervical pedicle screw placement: feasibility and accuracy of two new insertion techniques based on morphometric data. Eur Spine J 2007, 16(1):47-56.

26. Cloward RB: Treatment of acute fractures and fracture-dislocations of the cervical spine by vertebral-body fusion. A report of eleven cases. J Neurosurg 1961, 18:201-209.

27. Ebraheim NA, Haman ST, Xu R, Yeasting RA: The anatomic location of the dorsal ramus of the cervical nerve and its relation to the superior articular process of the lateral mass. Spine (Phila Pa 1976) 1998, 23(18):1968-1971.

28. Barrey C, Mertens P, Jund J, Cotton F, Perrin G: Quantitative anatomic evaluation of cervical lateral mass fixation with a comparison of the Roy-Camille and the Magerl screw techniques. Spine (Phila Pa 1976) 2005, 30(6):140-147.

29. Xu R, Haman SP, Ebraheim NA, Yeasting RA: The anatomic relation of lateral mass screws to the spinal nerves. A comparison of the Magerl, Anderson, and An techniques. Spine (Phila Pa 1976) 1999, 24(19):2057-2061.

30. Heller JG, Carlson GD, Abitbol JJ, Garfin SR: Anatomic comparison of the Roy-Camille and Magerl techniques for screw placement in the lower cervical spine. Spine (Phila Pa 1976) 1991, 16(Suppl 10):552-557.

31. Barrey C, Mertens P, Rumelhart C, Cotton F, Jund J, Perrin G: Biomechanical evaluation of cervical lateral mass fixation: a comparison of the Roy-Camille and Magerl screw techniques. J Neurosurg 2004, 100(Suppl 3):268-276.

32. Ulrich C, Arand M, Nothwang J: Internal fixation on the lower cervical spine-biomechanics and clinical practice of procedures and implants. Eur Spine J 2001, 10(2):88-100.

doi:10.1186/1475-925X-13-115

Cite this article as: Song et al: Four lateral mass screw fixation techniques in lower cervical spine following laminectomy: a finite element analysis study of stress distribution. BioMedical Engineering OnLine 2014 13:115.

\section{Submit your next manuscript to BioMed Central and take full advantage of:}

- Convenient online submission

- Thorough peer review

- No space constraints or color figure charges

- Immediate publication on acceptance

- Inclusion in PubMed, CAS, Scopus and Google Scholar

- Research which is freely available for redistribution

Submit your manuscript at www.biomedcentral.com/submit 